\title{
Room-temperature photogeneration of nitrosyl linkage isomers in ruthenium nitrosyl complexes
}

\author{
A.A. Mikhailov, ${ }^{[a, b]}$ E. Wenger, ${ }^{[c]}$ G.A. Kostin,${ }^{[a, b]}$ and D. Schaniel ${ }^{[c]}$ \\ [a] A.A. Mikhailov and Prof. G.A. Kostin \\ Nikolaev Institute of Inorganic Chemistry SB RAS, 3, Acad. Lavrentiev Ave., Novosibirsk, 630090, Russia \\ E-mail: amikhailov@niic.nsc.ru \\ [b] Novosibirsk State University, 1, Pirogova str., Novosibirsk, 630090, Russia \\ [c] Prof. Dr. D. Schaniel and Dr. E. Wenger \\ Université de Lorraine, CNRS, CRM2, UMR 7036, Nancy, 54000, France
}

\begin{abstract}
The conditions for the photogeneration of NO linkage isomers at room temperature are studied. By pulsed laser irradiation in the blue spectral range the long-lived Ru-ON isomer can be generated at room temperature, which is crucial for potential applications such as holography and data storage. Using static and time-resolved spectroscopy (UV/Vis and IR) we give evidence that the liftime of the $\mathrm{Ru}-\left(\mathrm{n}^{2}-(\mathrm{NO})\right)$ isomer is a decisive parameter for the formation of Ru-ON isomer at high temperature due to a two-step isomerization mechanism Ru-NO $\rightarrow \mathrm{Ru}-\left(\mathrm{n}^{2}-(\mathrm{NO})\right) \rightarrow \mathrm{Ru}-\mathrm{ON}$. Furthermore, we report the low temperature structures for each isomer, which were revealed by photocrystallography.
\end{abstract}

\section{Introduction}

Ruthenium nitrosyl coordination compounds are an interesting class of materials due to their ability to form photoinduced nitrosyl linkage isomers, an isonitrosyl Ru-ON (MS1) and a side-on Ru-( $\left.\eta^{2}-(\mathrm{NO})\right)(\mathrm{MS} 2)$ configuration, ${ }^{[1],[2]}$ as well as their potential for photodynamic therapy ${ }^{[3],[4]}$ In order to be exploitable in applications, such as holography ${ }^{[5],[6]}$ or data storage,$^{[7]}$ the underlying photoisomerization process needs to be understood in detail and should be producible at room temperature. In most cases, the generation and study of the linkage isomers is performed at low temperatures, where the MS1 and MS2 states exhibit an infinite lifetime. ${ }^{[8],[9],[10],[11]}$ Room temperature studies were performed using transient absorption spectroscopy ${ }^{[12]}$ and ultrafast pump-probe spectroscopy ${ }^{[13],[14],[15]}$ on an iron nitrosyl compound (Sodium Nitroprusside, $\left.\mathrm{Na}_{2}\left[\mathrm{FeNO}(\mathrm{CN})_{5}\right] 2 \mathrm{H}_{2} \mathrm{O}\right)$. In the solid state, up to now, only the MS2 isomer could be observed at room temperature. This corroborates the hypothesis that for the generation of MS1 a two-step mechanism is necessary, whereby

MS1 is generated by inducing with a first photon MS2 and a second photon transfers MS2 to MS1. ${ }^{[16],[17],[18],[19],[20]}$ In order to obtain MS1 one needs thus an overlap of GS and MS2 absorption bands in addition to the condition of a suitable relaxation path from the excited state to the linkage isomer energetic minimum (on the GS potential surface). ${ }^{[1]}$ Actually, according to $\mathrm{DFT}^{[18]}$ and MS-CASPT2 ${ }^{[17]}$ calculations the MS1 photogeneration pathway in $\left[\mathrm{RuCl}(\mathrm{NO})(\mathrm{py})_{4}\right]^{2+}$ is supposed to involve several nonadiabatic intersystem crossing (ISC) processes between the singlet and triplet states of all three involved isomers GS, MS2, and MS1 (see e.g. Fig. 1 in Ref.[17]). In the current work we will not address these ISC processes, since they occur on time scales not accessible in our experiments. The reader should thus bear in mind that by the term "two-step mechanism" we address a rather complicated multistep excitation-relaxation mechanism (for each step) of which we assess only the initial optical excitations as well as the thermal relaxation of GS, MS2 and MS1 within our experimental time resolution of a few nanoseconds.

In a recent work, ${ }^{[22]}$ we have shown that the $\mathrm{MS} 1$ linkage isomer in $\left[\mathrm{RuNO}(\mathrm{Py})_{4} \mathrm{~F}\right]\left(\mathrm{ClO}_{4}\right)_{2}$ can be generated by irradiation with $445 \mathrm{~nm}$ at low temperature $(80 \mathrm{~K})$ and that it exhibits the highest thermal stability of currently known NO linkage isomers. Furthermore, the MS2 linkage isomer can be generated by $980 \mathrm{~nm}$ irradiation of MS1. Given the rather long lifetime of MS1 ( 10 min) at room temperature, this system is suitable to study the room temperature properties of NO linkage isomers. In the current work, we will thus discuss the generation mechanism of the linkage isomers in $\left[\mathrm{RuNO}(\mathrm{Py})_{4} \mathrm{~F}\right]\left(\mathrm{ClO}_{4}\right)_{2}$ and especially explore the possibilities to generate the two linkage isomers at room temperature. For this purpose, we performed a systematic spectroscopic (UV/Vis and IR) study at low temperature and time-resolved 
experiments at room temperature. Furthermore, we report the low temperature structures for MS1 and MS2 obtained from X-ray diffraction.

\section{Results and Discussion}

\section{Photocrystallography investigations of GS, MS1 and MS2}

In order to attribute spectroscopic features to the structural changes, the structures of all three isomers - GS, MS1 and MS2 of $\left[\mathrm{RuNO}(\mathrm{Py})_{4} \mathrm{~F}\right]\left(\mathrm{ClO}_{4}\right)_{2}$ were determined by single crystal X-Ray diffraction at $100 \mathrm{~K}$ (See Fig. 1). We describe here briefly the main structural changes in the Ru-NO group, for the complete discussion of the structures see the Supplementary Material (Fig. S1 and S2). The ground state (GS) structure contains two non - equivalent structural units with Ru1 and Ru2 central atoms. Ru-N distances (of Ru-NO) are $1.750 \AA$, Ru-N-O angles are close to linear: Ru1-N11$\mathrm{O} 111=177.5(1)^{\circ}$, Ru2-N21-O211 = $179.1(1)^{\circ}$. After $420 \mathrm{~nm}$ irradiation (60 min, 500mW), the color of the crystal changed from bright yellow to deep green (See Fig. S3), and the Ru-NO (GS) coordinate changes to Ru-ON (MS1) with $92 \%$ population. The Ru-O bond distances in Ru-ON are $1.841 \AA$ with 177.7(1) and 178.7(1) ${ }^{\circ} \mathrm{Ru}-\mathrm{O}-\mathrm{N}$ angles for Ru1 and Ru2 respectively. After subsequent $920 \mathrm{~nm}$ irradiation (30 min, $400 \mathrm{~mW}$ ) of the same single crystal, the color changed from deep green to black (See Figure S3), and the structural parameters have been collected again. The MS2 isomer was found only for one structural unit with $17 \%$ population, with a Ru-N bond length of 2.00 (2) $\AA$ and a Ru-O bond length of $2.09(1) \AA$. The Ru-N-O angle is $80(1)^{\circ}$. These photocrystallographic results allow us to unambiguously assign the spectral bands described in the sections below to the GS, MS1, and MS2 structures.

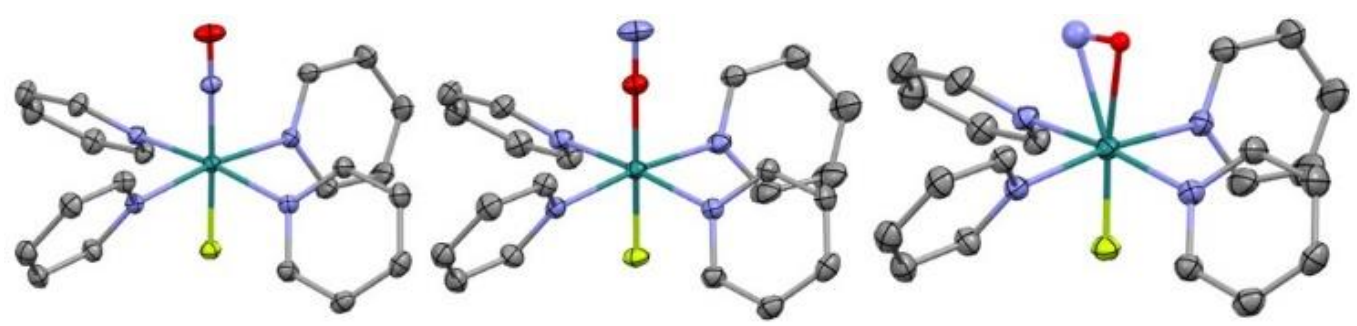

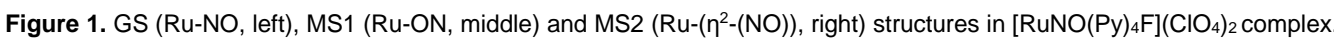

\section{Low-temperature spectroscopy studies of linkage isomers}

In order to find the optimal spectral range for photogeneration of MS1 and MS2 we performed a systematic infrared spectroscopic study using wavelengths in the range 365 - $1050 \mathrm{~nm}$ for population and depopulation of MS1 and MS2. Our results indicate that irradiation in the blue spectral range is the most efficient for transferring of GS to MS1 (Fig. 2). Under 405-470 nm exposure of GS, MS1 is generated as evidenced by two absorption bands with maxima at 1762 and $1768 \mathrm{~cm}^{-1}$. Upon generation of MS1, the GS bands (two maxima at 1900 and $1912 \mathrm{~cm}^{-1}$ ) decrease. Upon irradiation of MS1 using light in the $850-1050 \mathrm{~nm}$ spectral range, two simultaneous reactions occur - MS1 to GS and MS1 to MS2. The appearance of MS2 is reflected in the formation of bands with maxima at 1565 and $1580 \mathrm{~cm}^{-1}$. The generation of MS2 is accompanied by a decreasing of MS1 and an increasing of GS bands. Population of both MS was determined from the decrease of the area of the GS band and amount to $40 \%$ for MS1 and $10 \%$ for MS2. Irradiation with 365 and $505-780 \mathrm{~nm}$ light induces a bleaching of both MS1 and MS2 (See Fig. S7). The presence of two absorption bands for the nitrosyl stretching vibration band is due to two non-equivalent structural units in the unit cell. A summary of the wavelength dependence of the GS-MS transformations under light exposure is given in Figure S8. 

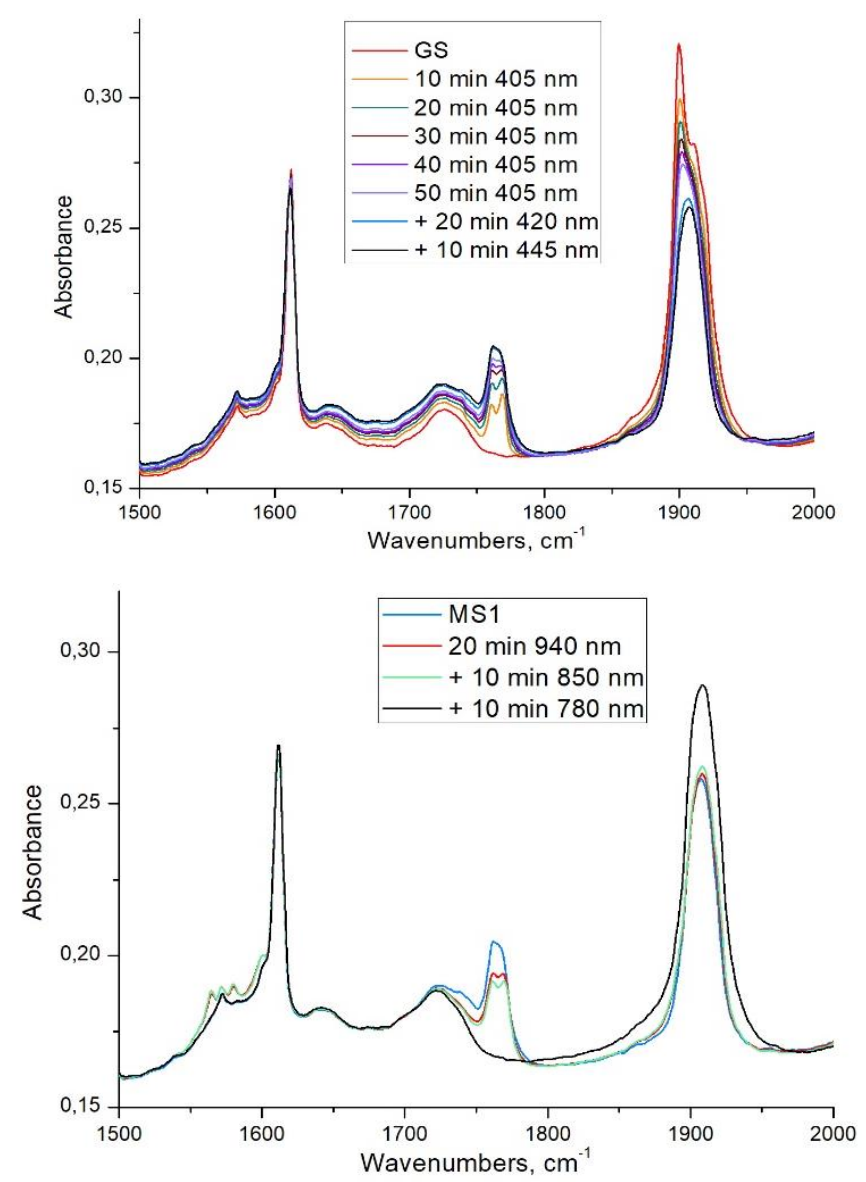

Figure 2. (Top) Decrease of GS bands $\left(1900 / 1912 \mathrm{~cm}^{-1}\right)$ and increase of MS1 bands $\left(1762 / 1768 \mathrm{~cm}^{-1}\right)$ as a function of exposure to blue light (405 - $445 \mathrm{~nm}$ ) at $100 \mathrm{~K}$ (exposure time increases from red line = GS to black line). (Bottom) Decrease of MS1 bands $\left(1762 / 1768 \mathrm{~cm}^{-1}\right)$ and increase of MS2 bands $\left(1565 / 1580 \mathrm{~cm}^{-1}\right)$ and GS bands $\left(1900 / 1912 \mathrm{~cm}^{-1}\right)$ as a function of irradiation in the near infrared spectral range: $940 \mathrm{~nm}$ (red line), 850 $\mathrm{nm}$ (green line), and $780 \mathrm{~nm}$ (black line).

In order to gain more insight into the population and depopulation processes of MS1 and MS2, the UV-vis spectra of the complex after light irradiation were measured at $100 \mathrm{~K}$ (See Fig. 3). The GS (red line) exhibits strong absorption from the deep UV up to the $500 \mathrm{~nm}$ region, while the MS1 (blue line) spectrum has another maximum around $660 \mathrm{~nm}$. Concerning the MS2 (green line), it exhibits the strongest absorption with respect to GS and MS1 in the $500-600 \mathrm{~nm}$ region. Further irradiation of MS1 or MS2 by $780 \mathrm{~nm}$ light results in the spectrum marked in black, which is the same as the spectrum of GS except for an incomplete resumption of the band at $\sim 400 \mathrm{~nm}$. We attribute this difference to some nitric oxide release and the formation of the nitrosyl-deficient complex after long irradiation times (See Fig. S9). The UVvis spectra give a first insight into the wavelength dependence of the MS1/MS2 population (See Fig. S8). GS can be transferred to MS1 by the $405-470 \mathrm{~nm}$ irradiation due to the strong absorption band at $405-470 \mathrm{~nm}$ region. As the absorbance of both MS1 and MS2 are shifted to the UV $(365 \mathrm{~nm})$ and the yellow - red $(505-780 \mathrm{~nm})$ spectral range with respect to GS, light irradiation in this region transfers MS1 and MS2 back to GS. Note that infrared light exposure (850 $1050 \mathrm{~nm}$ ) of MS1 opens the possibility to transfer MS1 to MS2. This indicates that the cross section for the transfer MS1MS2 in this region is higher than that for MS2-GS (and/or MS1-GS). 


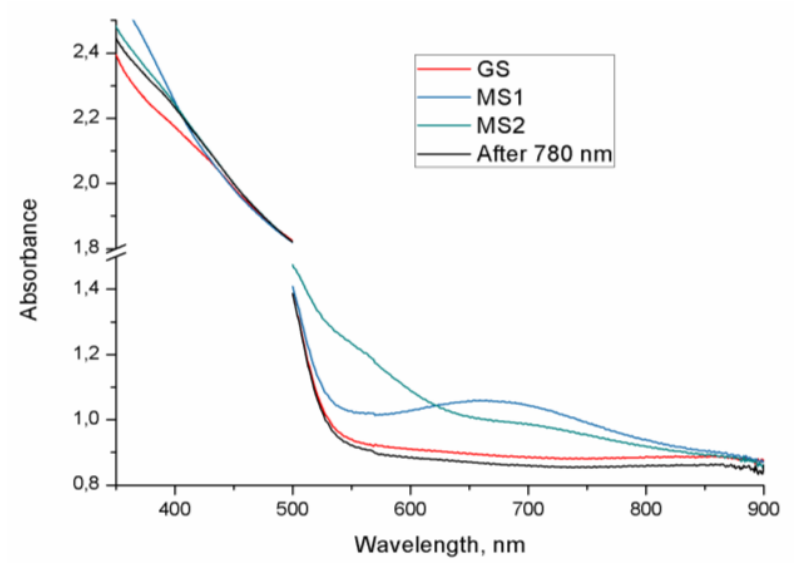

Figure 3. UV/vis spectra of GS at $100 \mathrm{~K}$ (red line, before irradiation), GS+MS1 (blue line, after 30 min of $445 \mathrm{~nm}$ ), GS+MS1+MS2 (green line, after $100 \mathrm{~min}$ of $940 \mathrm{~nm}$ ), and GS (black, after $30 \mathrm{~min}$ of $780 \mathrm{~nm}$ ). The $350-500 \mathrm{~nm}$ range of the spectra was obtained from the $\left[\mathrm{RuNOPy}_{4} \mathrm{~F}\right]\left(\mathrm{ClO}_{4}\right)_{2}$ complex in $\mathrm{KBr}$ pellet, the $500-900 \mathrm{~nm}$ range of the spectra from a [RuNOPy$\left.{ }_{4} \mathrm{~F}\right]\left(\mathrm{ClO}_{4}\right)_{2}$ single crystal.

The kinetic parameters of MS1 to GS and MS2 to GS reactions were determined by Differential Scanning Calorimetry (DSC) earlier ${ }^{[22]}$. Namely, the activation energy $\left(E_{a}\right)$ and frequency factor $\left(\lg \mathrm{k}_{0}\right)$ are $98.8(4.3) \mathrm{kJ} / \mathrm{mol}$ and $14.9(0.7)$, and $47.5(4.2) \mathrm{kJ} / \mathrm{mol}$ and 10.4 (1.1) for MS1 - GS and MS2 - GS reactions respectively. According to this data, the lifetime ( $k^{1}$ from the Arrhenius equation) of MS1 isomer at room temperature $(293 \mathrm{~K})$ is $9 \mathrm{~min}$, which could provide the possibility to form the MS1 isomer at room temperature, not only at $80-100 \mathrm{~K}$. However, irradiating during $10 \mathrm{~min}$ with $445 \mathrm{~nm}$ and $100 \mathrm{~mW}$ at room temperature does not yield a measureable MS1 signal in the infrared spectrum. In order to shine light on this behaviour we performed a temperature dependent study, where we repeated the same irradiation procedure $(445 \mathrm{~nm}, 10 \mathrm{~min}, 100 \mathrm{~mW})$ at each temperature, before measuring the IR spectrum. We observe that the formation of MS1 under these conditions is only possible below temperatures of $230 \mathrm{~K}$ (Fig. 4.). The lifetime of MS1 at $230 \mathrm{~K}$ is $3.5 \cdot 10^{7} \mathrm{~s}$, which indicates that it is not the lifetime of MS1 that prevents its detection (routine time of spectrum scan is $1 \mathrm{~min}$ ). According to theoretical ${ }^{[18]}$ as well as low-temperature absorption spectroscopy studies ${ }^{[16]}$ of the nitrosyl isomerization mechanism in $\left[\mathrm{RuNOPy}_{4} \mathrm{Cl}\right]^{2+}$, the GS - MS1 reaction include the intermediate state MS2 and should be described as two step GS - MS2 - MS1 process. The lifetime of MS2 in $\left[\mathrm{RuNOPy}{ }_{4} \mathrm{~F}\right]\left(\mathrm{ClO}_{4}\right)_{2}$ at $230 \mathrm{~K}$ is $3 \mathrm{~s}$ (extrapolated from the DSC data). It seems thus probable that under the assumption of a GS - MS2 - MS1 mechanism of isomerization we encounter a temperature restriction of MS1 generation due to the small MS2 lifetime at high temperature, i.e. at high temperature (higher than $230 \mathrm{~K}$ ) the probability of the second step, the MS2 - MS1 transformation, is very low, since the lifetime of MS2 is too small for "catching» of the second photon, especially in the case of a relatively low photon flux provided by an LED (445 mn, $100 \mathrm{~mW}$ ). Indeed, if we compare our data with the data of other ruthenium complexes (See Table 1), there is a correlation between the maximum temperature at which MS1 can be populated and the lifetime of MS2 at this temperature. It seems that for different ruthenium complexes the lifetime of MS2 needs to be in the range of some seconds, in order to generate MS1 using irradiation with LED. 


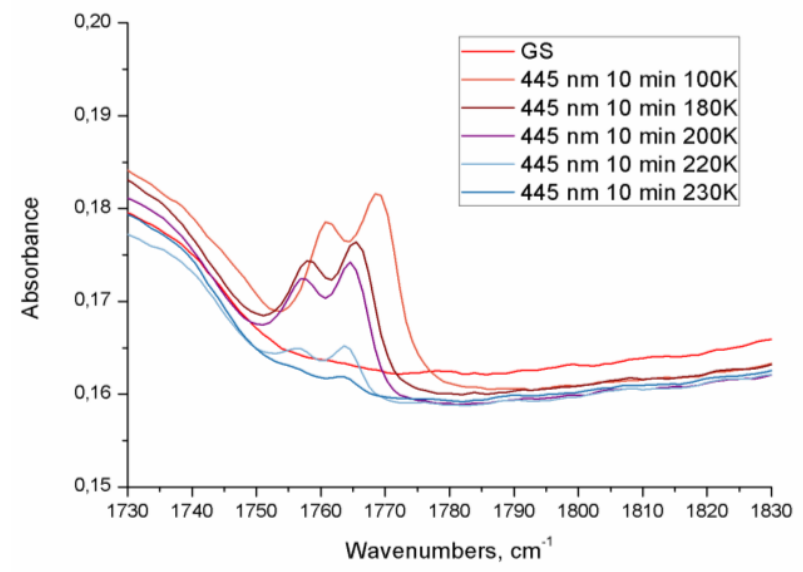

Figure 4. The generation of the MS1 isomer (445 nm, $10 \mathrm{~min}, 100 \mathrm{~mW}$ ) at different temperatures: $100 \mathrm{~K}$ (orange line), $180 \mathrm{~K}$ (brown line), $200 \mathrm{~K}$ (purple line), $220 \mathrm{~K}$ (blue line), $230 \mathrm{~K}$ (dark blue line). The MS1 populations at these temperatures are 15, 8, 7, 3 and 1\% respectively.

Table 1. Comparison of the maximum temperature $T_{\max }$ at which MS1 can be populated with the lifetime of MS2 at $T_{\max }$ for different ruthenium nitrosyl complexes.

\begin{tabular}{|c|c|c|c|}
\hline Complex & $\mathrm{T}_{\max }, \mathrm{K}$ & MS2 lifetime, s & Ref. \\
\hline$\left[\mathrm{RuNOP}_{4} \mathrm{Cl}\right]\left(\mathrm{PF}_{6}\right)_{2}$ & 180 & 6 & [23] \\
\hline$\left[\mathrm{RuNO}\left(\mathrm{NH}_{3}\right)_{4}\left(\mathrm{H}_{2} \mathrm{O}\right)\right] \mathrm{Cl}_{3}$ & 250 & 3 & [9] \\
\hline$\left[\mathrm{RuNO}\left(\mathrm{NH}_{3}\right)_{5}\right] \mathrm{Cl}_{3}$ & 240 & 15 & [9] \\
\hline$\left[\mathrm{RuNOPy}{ }_{4} \mathrm{~F}\right]\left(\mathrm{ClO}_{4}\right)_{2}$ & 230 & 3 & Pr. work \\
\hline
\end{tabular}

\section{Generation of MS1 and MS2 at room temperature}

Since the ratio between source power (watts or photons per second) and MS2 lifetime is crucial, we used a pulsed laser $(10 \mathrm{~Hz}, 10 \mathrm{~mJ}, 445 \mathrm{~nm}, 5 \mathrm{~ns})$ for generating MS1 at room temperature. The IR spectra of $\left[\mathrm{RuNOPy}{ }_{4} \mathrm{~F}\right]\left(\mathrm{ClO}_{4}\right)_{2}$ in $\mathrm{KBr}$ after 3 min of pulse laser irradiation at $\approx 300 \mathrm{~K}$ are shown in Fig. 5 . The position of the newly generated bands is the same (1755 and $1761 \mathrm{~cm}^{-1}$ ) as in the low temperature experiment after blue light exposure, the slight shift to lower energy of 7 $\mathrm{cm}^{-1}$ is expected due to the higher temperature. These generated bands decay with a lifetime of $151 \mathrm{~s}$, which corresponds to the calculated MS1 lifetime at $302 \mathrm{~K}$. Hence, according to the position and decay time of the band, we assign the band to the MS1 NO stretching vibration. There were no measurable changes in the IR spectrum in the case of less than $1 \mathrm{~min}$ of pulsed irradiation with $445 \mathrm{~nm}$ as well as in the case of pulsed irradiation with $590 \mathrm{~nm}$ for $3 \mathrm{~min}$. The fact that MS1 can be photogenerated at room temperature using pulse light source is in agreement with the proposed two-step generation mechanism GS - MS2 - MS1. The higher photon flux per unit time provided by the short pulse increases the probability to induce the second step MS2-MS1. To the best of our knowledge, this is the first example of MS1 formation at room temperature in the solid state for ruthenium nitrosyl complexes.
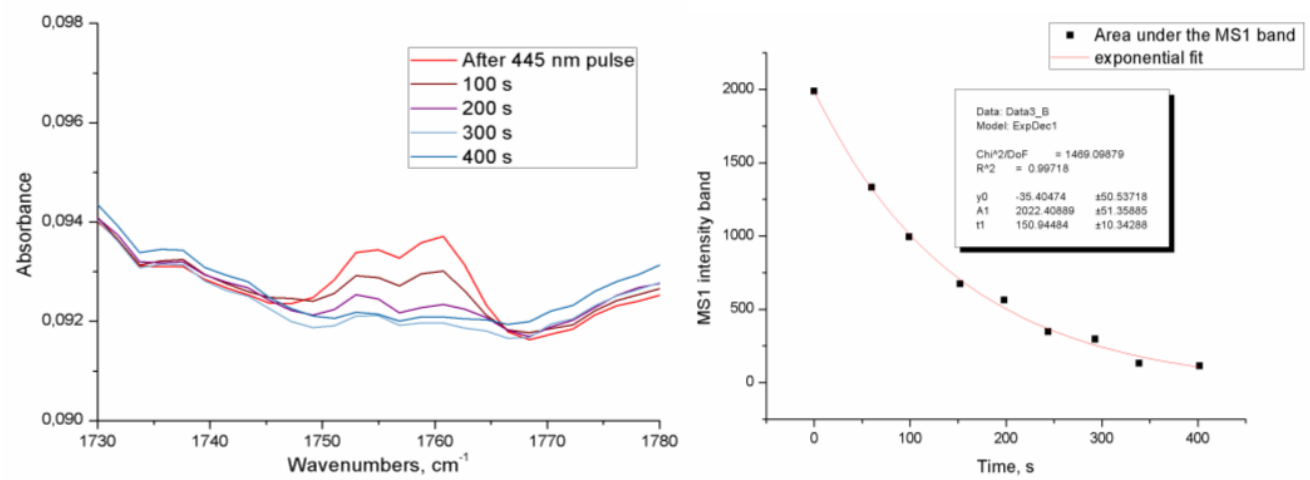

Figure 5. (Top) IR spectra of $\left[\mathrm{RuNOPy}{ }_{4} \mathrm{~F}\right]\left(\mathrm{ClO}_{4}\right)_{2}$ in $\mathrm{KBr}$ after $3 \mathrm{~min}$ of pulse laser irradiation at $\approx 300 \mathrm{~K}$ as a function of time. (Bottom) Monoexponential fit of the band area during the decay. The lifetime of the band is $151 \mathrm{~s}$ at $\approx 300 \mathrm{~K}$, the band's decay is assigned to the MS1 thermal decay process. 
In order to further support the proposed isomerization mechanism (GS - MS2 - MS1), the light - induced absorption at room temperature has been measured using transient pump - probe spectroscopy. Temporal decay of the light-induced absorption after pumping with a $445 \mathrm{~nm}$ laser pulse in a $\left[\mathrm{RuNOPy}{ }_{4} \mathrm{~F}\right]\left(\mathrm{ClO}_{4}\right)_{2}$ single crystal is shown in Fig. 6 and Fig. S10. The absorption decay is fitted by mono-exponential kinetic and characterized by a 8.5 - $18 \mathrm{~ms}$ lifetime, for different probe wavelengths. According to DSC data, the lifetime of the MS2 isomer at $300 \mathrm{~K}$ is $7.5 \mathrm{~ms}$, which suggests, that the detected light-induced absorption change corresponds to the MS2 state and its thermal decay process. All findings show, that after excitation of $\left[\mathrm{RuNOPy}{ }_{4} \mathrm{~F}\right]\left(\mathrm{ClO}_{4}\right)_{2}$ with a single laser pulse a significant amount of the MS2 state can be populated, while the MS1 population is too small to be detected in our experiment. Long-time irradiation with a pulsed laser ( 3 minutes with $10 \mathrm{~Hz}$ repetition rate corresponding to 1800 pulses) allows to generate a measurable amount of MS1 state by a sequential two-step photon absorption from GS to MS2 to MS1. Note that the generation of MS1 occurs within one single laser pulse, since the MS2 state relaxes faster than $100 \mathrm{~ms}$, the delay between two laser pulses in our experiment. From literature we know that the photoisomerization from GS to MS2 is complete within a few picoseconds ${ }^{[13]}{ }^{[14]}$, so that there remains enough time in the MS2 state to absorb a second photon of the $5 \mathrm{~ns}$ long impinging laser pulse. However, based on the methods used in this work we cannot decipher the details of the complicated isomerization mechanism via non-adiabatic processes and interplay between singlet and triplet channels proposed by theory ${ }^{[17],[18]}$. Notwithstanding, our results are unambiguous experimental evidence for the two-step mechanism (GS-MS2-MS1) of nitrosyl ligand photoisomerization within the meaning that two photons are needed to drive the system from GS to MS1 (via MS2). Most importantly, our results show that, given the appropriate wavelength and photon flux, MS1 can be generated at room temperature.

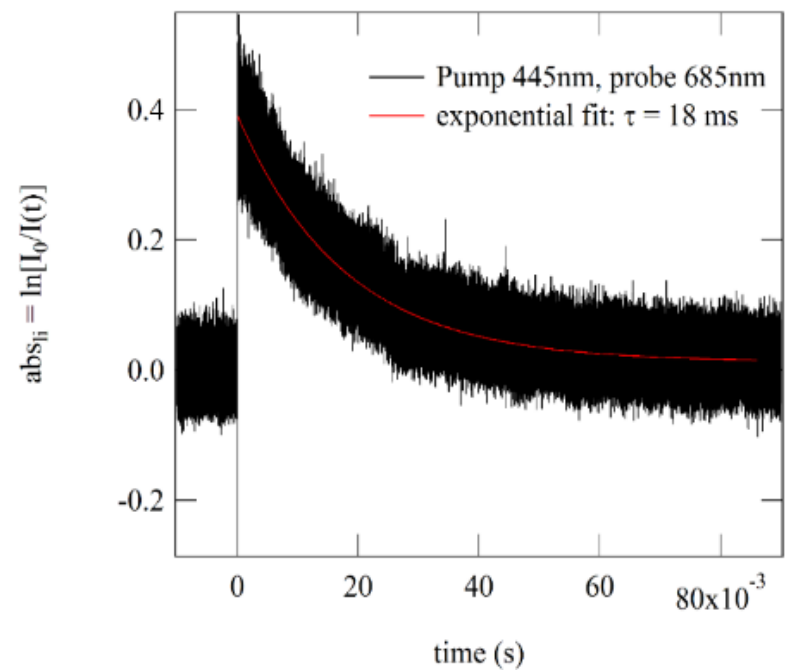

Figure 6. Light-induced absorption changes in $\left[\mathrm{RuNOPy}{ }_{4} \mathrm{~F}\right]\left(\mathrm{ClO}_{4}\right)_{2}$ single crystal after pumping at $445 \mathrm{~nm}$ ( $5 \mathrm{~ns}$ laser pulse) and probing at $685 \mathrm{~nm}$. The experimental data is fitted by mono-exponential kinetic yielding a lifetime of $18 \mathrm{~ms}$.

\section{Conclusions}

The described results for the generation of nitrosyl linkage isomers at room temperature open new avenues for the activation of small molecules by light. As was shown, due to the two-stage isomerization mechanism GS-MS2-MS1, the short life-time intermediate MS2 could restrict the formation of the long-lived MS1 isomer. This main drawback for room temperature applications can be overcome by using a sufficiently high photon flux as given, e.g., by a pulsed laser source. Since each linkage isomer has particular absorption properties, the proper choice of the photoexcitation wavelength will allow to drive the isomerization route. 


\section{Experimental Section}

\section{Synthesis of trans-[RuNO$\left.(\mathrm{Py})_{4} \mathrm{~F}\right]\left(\mathrm{ClO}_{4}\right)_{2}$}

Synthesis of $\left[\mathrm{RuNO}(\mathrm{Py})_{4} \mathrm{~F}\right]\left(\mathrm{ClO}_{4}\right)_{2}$ was performed as described in previous work. ${ }^{[22]}$ Short description is given: $347 \mathrm{mg}$ of [RuNO $\left.(\mathrm{Py})_{4} \mathrm{OH}\right]\left(\mathrm{PF}_{6}\right)_{2}$ was dissolved in $10 \mathrm{~mL}$ of $\mathrm{HF}$ and heated in a closed polypropylene vessel for $6 \mathrm{~h}$ at $85^{\circ} \mathrm{C}$. The solution then was evaporated in air to a minimum volume and $6 \mathrm{~mL}$ of $6 \mathrm{M} \mathrm{HClO}_{4}$ was added. The yellow powder of $\left[\mathrm{RuNO}(\mathrm{Py})_{4} \mathrm{~F}\right]\left(\mathrm{ClO}_{4}\right)_{2}$ complex was precipitated by diethyl ether, filtered and washed with diethyl ether. The yield of $\left[\mathrm{RuNO}(\mathrm{Py})_{4} \mathrm{~F}\right]\left(\mathrm{ClO}_{4}\right)_{2}$ is $72 \%$. The single crystals of $\left[\mathrm{RuNO}(\mathrm{Py})_{4} \mathrm{~F}\right]\left(\mathrm{ClO}_{4}\right)_{2}$ used for all measurements were obtained by recrystallization from water.

\section{Infrared and UV/vis spectroscopy}

Infrared spectroscopy measurements with irradiation were performed using a Nicolet 5700 FT-IR spectrometer with a resolution of 2 $\mathrm{cm}^{-1}$ in the range $400-4000 \mathrm{~cm}^{-1}$. The sample was grinded, mixed with $\mathrm{KBr}$, and pressed into pellets. $\mathrm{KBr}$ pellets were bonded by silver paste on the coldfinger of a closed cycle cryostat (Oxford Optistat V01) and irradiated by LED through $\mathrm{KBr}$ windows with light of different wavelengths in the range $365-1050 \mathrm{~nm}$ and $15-150 \mathrm{~mW}$ optical power. The cryostat allows controlling the temperature in the range of 9-320 K. UV/vis spectra were recorded using transparent KBr pellets or single crystals of the complex with a Varian CARY 4000 spectrometer. Transparent pellets were prepared as for IR measurements. Low-temperature measurements were performed using the same cryostat as for IR measurements, except that $\mathrm{KBr}$ windows were exchanged for standard borosilicate glass windows. For singlecrystal measurements, the single crystals were mounted on a diaphragm, in order to block all parts of the probe beam not passing through the sample. The baseline was measured using the same diaphragm, which can be mounted on the cryostat sample holder.

\section{Pump-Probe Transient Absorption Spectroscopy}

The optical pump system consists of a Surelite II-10 Nd-YAG pulsed laser equipped with an optical parametric oscillator (OPO, model SLOPO+). The system delivers laser pulses with 3-5 ns duration at a frequency of $10 \mathrm{~Hz}$. The OPO is tunable in the range $400-700 \mathrm{~nm}$. The laser beam is directed to the sample position (single crystal or KBr pellet) using a series of silver-coated mirrors and precisely adjusted and focused through appropriate lenses $(f=100,200$, or 300 ) to illuminate the sample uniformly (i.e. the beam diameter is larger than the sample). For the transient absorption measurements cw-LASERs at different wavelengths ( $532 \mathrm{~nm}, 635 \mathrm{~nm}$ and $685 \mathrm{~nm}$ ) are used to probe the light-induced absorption. The probe beam is focused by a lens $(f=300)$ on the sample position such that the probe beam diameter is smaller than the pump beam diameter. Its intensity can be adjusted by a $\lambda / 2$ waveplate and a polarizer from a few $\mathrm{mW}$ to a few $\mu \mathrm{W}$. The probe light is detected by a $200 \mathrm{MHz}$ Si-Pin diode from Femto Messtechnik GmbH. The voltage at the output of the detector is sampled using a 1.5-GHz oscilloscope (Lecroy Wavepro 715zi). The trigger is obtained directly from the LASER control system (delay of $10 \mathrm{~ns}$ with respect to the arrival of the pump beam on the sample position). In order to block the pump light (445 $\mathrm{nm}$ ) appropriate color filters (OG515 or OG590) and interference filters at the corresponding probe wavelengths (width of $5 \mathrm{~nm}$ ) are mounted in front of the photodiode. The system allows either single-shot excitation or repetitive excitation with $10 \mathrm{~Hz}$. In the single-shot mode the pump pulse is triggered by manual control and the delay time between two pulses and the recording time can be adjusted at will. The transient absorption signal is recorded in single-shot mode and averaged over 20 pump-probe cycles. For the infrared spectroscopic experiments the $\mathrm{KBr}$ pellets of $\left[\mathrm{RuNO}(\mathrm{Py})_{4} \mathrm{~F}\right]\left(\mathrm{ClO}_{4}\right)_{2}$ are excited in the $10 \mathrm{~Hz}$ mode, i.e. the delay between two pump pulses is $100 \mathrm{~ms}$. The exposure time is monitored by a chronometer to $1 \mathrm{~min}$ or $3 \mathrm{~min}$, corresponding to 600 and 1800 pulses respectively. The pulse intensity (measured over the beam size of $13 \mathrm{~mm}$ diameter covering the $\mathrm{KBr}$ pellet size) is $100 \mathrm{~mW}$ (corresponding to $10 \mathrm{~mJ} / \mathrm{pulse}$ ) at $445 \mathrm{~nm}$.

\section{Single crystal X-ray diffraction}

One unique single crystal of $\left[\mathrm{RuNO}(\mathrm{Py})_{4} \mathrm{~F}\right]\left(\mathrm{ClO}_{4}\right)_{2}$ was selected and measured with a D8 Venture Bruker 4 circles diffractometer. This diffractometer is equipped with an Incoatec $\mathrm{l} \mu \mathrm{S}$ microfocus $\mathrm{X}$-ray source with a Molybdenum anode (MoKa, $\lambda=0.71073 \AA$ ) and a PHOTON II detector. An Oxford Cryosystems Cryostream nitrogen blower was used to fix the sample temperature. Using Olex2, ${ }^{[24]}$ structures were solved with the $\mathrm{XS}^{[25]}$ structure solution program using Direct Methods and refined with the $\mathrm{XL}^{[25]}$ refinement package using Least Squares minimization. For irradiation procedures $420 \mathrm{~nm} 500 \mathrm{~mW}$ and $920 \mathrm{~nm} 400 \mathrm{~mW}$ LED were used for generating of MS1 and MS2 respectively. All X-Ray experiments were carried on the same single crystal. Structures have been deposited in CCDC with code numbers 1900341, 1900344, 1900342, 1900343 for GS, MS1, MS2 and GS after relaxation respectively.

\section{Acknowledgements}

This work was supported by the Comprehensive Program of Fundamental Research (Project 19-03-00594 A). Also, we thank Federal Agency for Scientific Organizations for funding. Artem Mikhailov is grateful for financial support from the Eiffel excellence bourse program (Grant P730329G). 


\section{References}

[1] P. Coppens, I. Novozhilova, A. Kovalevsky, Chem. Rev. 2002, 102, 861-884.

[2] D. V. Fomitchev, P. Coppens, Inorg. Chem. 1996, 35, 7021-7026.

[3] R. R. Allison, C. Sheng, R. Cuenca, V. S. Bagnato, C. Austerlitz, C. H. Sibata, Photodiagnosis Photodyn. Ther. 2010, 7, 115-119.

[4] A. A. Mikhailov, V. A. Vorobyev, V. A. Nadolinny, Y. V. Patrushev, Y. S. Yudina, G. A. Kostin, J. Photochem. Photobiol. A Chem. 2019, 373, 37-44.

[5] D. Schaniel, M. Imlau, T. Weisemoeller, T. Woike, K. W. Krämer, H.-U. Güdel, Adv. Mater. 2007, 19, $723-726$.

[6] M. Goulkov, D. Schaniel, T. Woike, J. Opt. Soc. Am. B 2010, 27, 927.

[7] T. Woike, W. Kirchner, G. Schetter, T. Barthel, K. Hyung-sang, S. Haussühl, Opt. Commun. 1994, 106, 6-10.

[8] B. Cormary, I. Malfant, M. Buron-Le Cointe, L. Toupet, B. Delley, D. Schaniel, N. Mockus, T. Woike, K. Fejfarová, V. Petř́ček, et al., Acta Crystallogr. Sect. B Struct. Sci. 2009, 65, 612-623.

[9] D. Schaniel, T. Woike, B. Delley, C. Boskovic, D. Biner, K. W. Krämer, H. U. Güdel, Phys. Chem. Chem. Phys. 2005, 7, 1164-1170.

[10] G. A. Kostin, A. O. Borodin, A. A. Mikhailov, N. V. Kuratieva, B. A. Kolesov, D. P. Pishchur, T. Woike, D. Schaniel, Eur. J. Inorg. Chem. 2015, 29, 4905-4913.

[11] G. A. Kostin, A. A. Mikhailov, N. V. Kuratieva, D. P. Pischur, D. O. Zharkov, I. R. Grin, New J. Chem. 2017, 41, 77587765.

[12] D. Schaniel, T. Woike, C. Merschjann, M. Imlau, Phys. Rev. B 2005, 72, 195119.

[13] D. Schaniel, M. Nicoul, T. Woike, Phys. Chem. Chem. Phys. 2010, 12, 9029-9033.

[14] G. Gallé, M. Nicoul, T. Woike, D. Schaniel, E. Freysz, Chem. Phys. Lett. 2012, 552, 64-68.

[15] M. S. Lynch, M. Cheng, B. E. Van Kuiken, M. Khalil, J. Am. Chem. Soc. 2011, 133, 5255-5262.

[16] L. Khadeeva, W. Kaszub, M. Lorenc, I. Malfant, M. Buron-Le Cointe, Inorg. Chem. 2016, 55, 4117-4123.

[17] F. Talotta, J.-L. Heully, F. Alary, I. M. Dixon, L. González, M. Boggio-Pasqua, J. Chem. Theory Comput. 2017, 13, $6120-6130$.

[18] J. Sanz García, F. Alary, M. Boggio-Pasqua, I. M. Dixon, I. Malfant, J.-L. Heully, Inorg. Chem. 2015, 54, 8310-8318.

[19] D. Schaniel, T. Woike, C. Boskovic, H. U. Güdel, Chem. Phys. Lett. 2004, 390, 347-351.

[20] S. I. Gorelsky, A. B. P. Lever, Int. J. Quantum Chem. 2000, 80, 636-645.

[21] D. Schaniel, T. Woike, Phys. Chem. Chem. Phys. 2009, 11, 4391-4395.

[22] G. A. Kostin, A. A. Mikhailov, N. V Kuratieva, D. P. Pishchur, A. N. Makhinya, New J. Chem. 2018, 42, 18928-18934.

[23] D. Schaniel, B. Cormary, I. Malfant, L. Valade, T. Woike, B. Delley, K. W. Krämer, H. U. Güdel, Phys. Chem. Chem. Phys. 2007, 9, 3717-3724.

[24] O. V. Dolomanov, L. J. Bourhis, R. J. Gildea, J. A. K. Howard, H. Puschmann, J. Appl. Crystallogr. 2009, 42, $339-341$. 
[25] G. M. Sheldrick, Acta Crystallogr. Sect. A Found. Crystallogr. 2008, 64, 112-122. 


\section{Supplementary materials}

\section{Structures of GS, MS1 and MS2}

\section{GS structure refinement}

The GS structure of the complex is comparable to the one from previous work ${ }^{[1]}$. The unit cell contains two non - equivalent structural units with Ru1 and Ru2 central atoms (See Figures S1 and S2). The cell parameters are given in Table S1. Ru-N bond distances in the Ru-NO groups are 1.751(1) and 1.750(1) $\AA$ for Ru1 and Ru2 respectively (See Table S2). The $\mathrm{N}-\mathrm{O}$ distances of the $\mathrm{NO}$ groups are equal: $\mathrm{N}-\mathrm{O}=$ 1.141(2) $\AA$. The Ru-N-O angles are close to linear: Ru1-N11-O111 = 177.5(1) $)^{\circ}$ Ru2-N21-O211 = 179.1(1) ${ }^{\circ}$. The average distances between $\mathrm{Ru}$ and planar $\mathrm{N}$ atoms of pyridine ligands are 2.092(2) and

2.098(2) $\AA$ for Ru1 and Ru2, respectively. The average angles between $\mathrm{N}$ donor pyridine atom, ruthenium and N11(N21) atom of nitrosyl ligand are 93.5(5) and 94.0(4) ${ }^{\circ}$ for Ru1 and Ru2, respectively (See Table $\mathrm{S} 1)$. Pyridine rings demonstrate a propeller like type, as found for the $\left[\mathrm{RuNOPy}_{4} \mathrm{Cl}\right]\left(\mathrm{PF}_{6}\right)_{2} \mathrm{complex}^{[2]}$. $\mathrm{Ru}^{-}$ F distances show significant differences: Ru1-F1 = 1.960(1) $\AA$ and Ru2-F2 = 1.914(1) $\AA$, which could be attributed to the packing features of each structural unit. The nitrosyl groups are each surrounded by three perchlorates anions. The corresponding O-O closest distances are O111-O43=2.760(3) $\AA$, O111-O34=

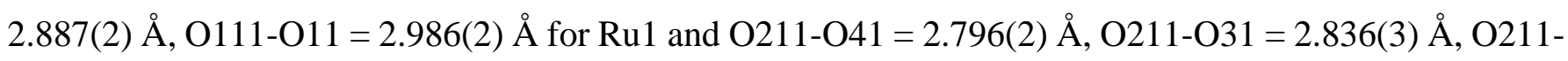
$\mathrm{O} 21=3.129(2) \AA$ for Ru2.

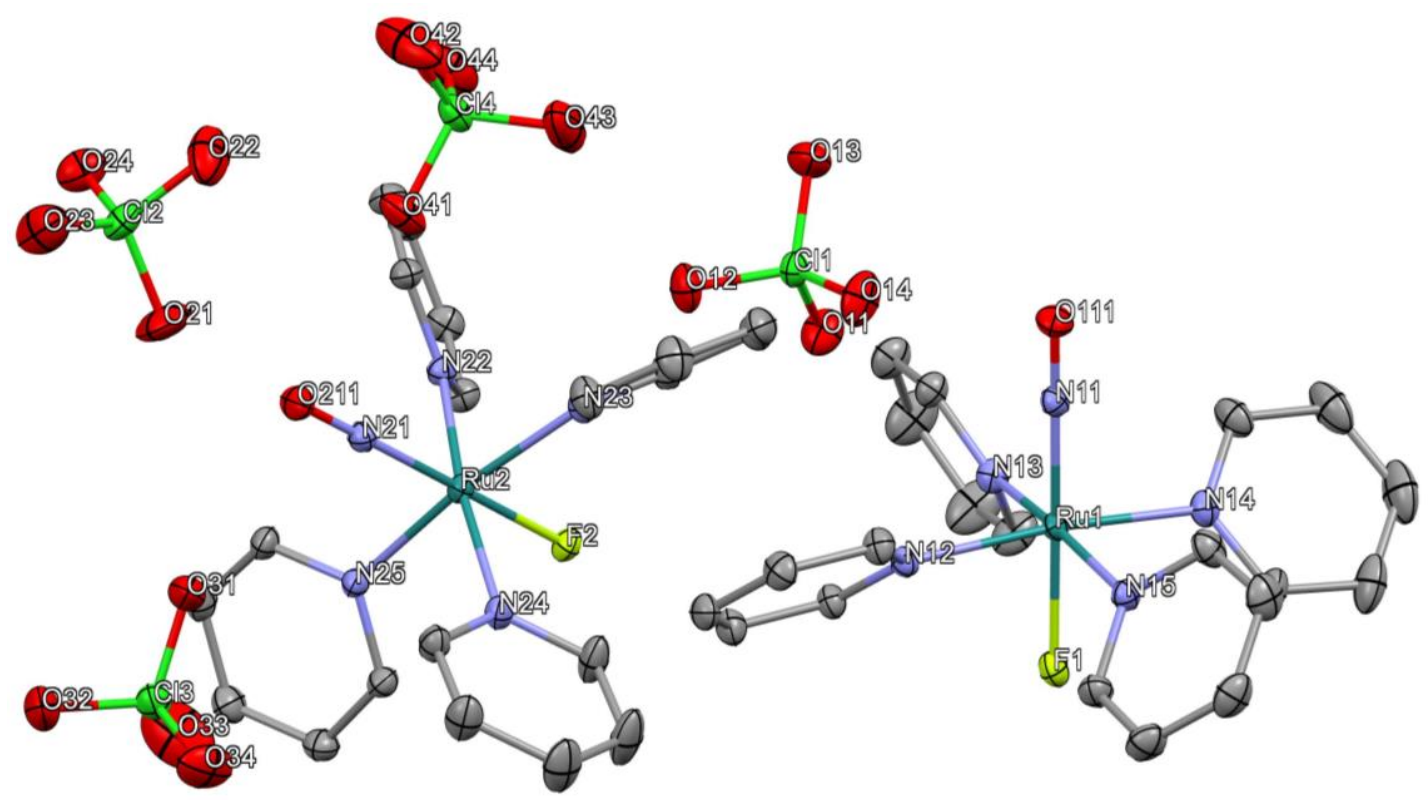

Figure S1. GS structure of $[\mathrm{RuNOPy} 4 \mathrm{~F}]\left(\mathrm{ClO}_{4}\right)_{2}$ complex. Hydrogen atoms are omitted. 

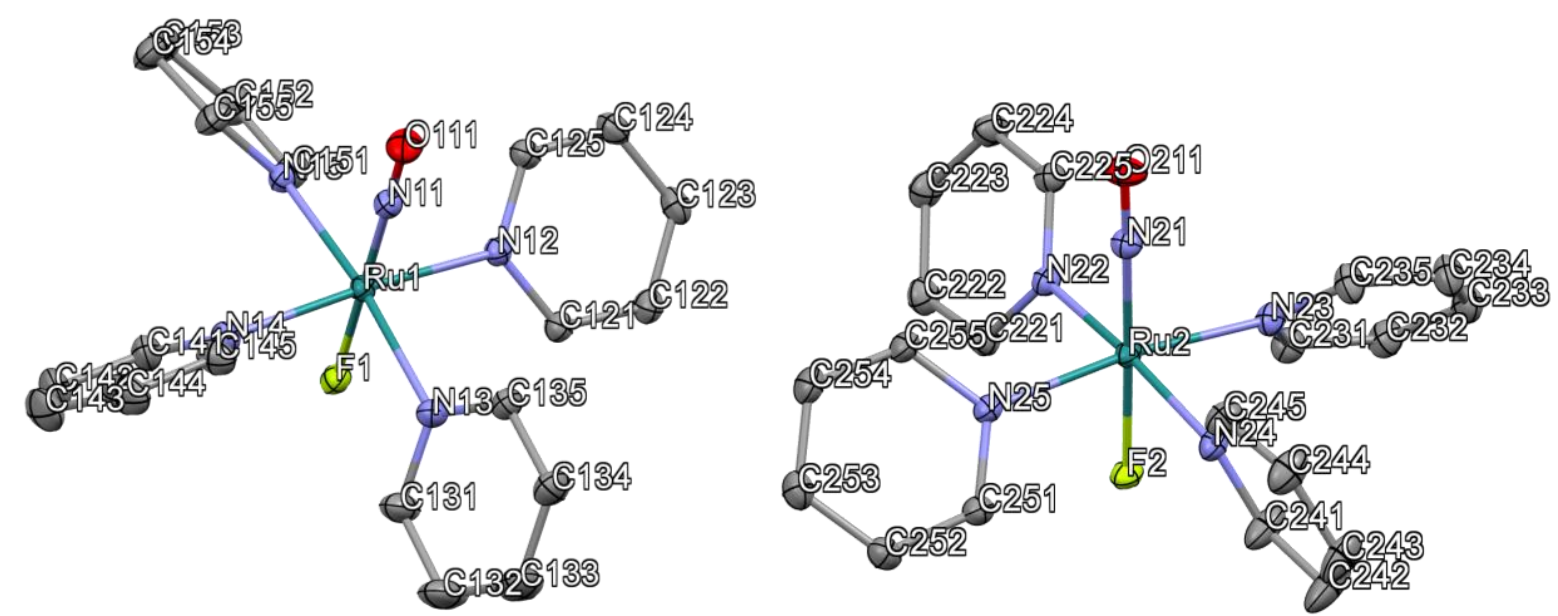

Figure S2. GS structure of $[\mathrm{RuNOPy} 4 \mathrm{~F}]\left(\mathrm{ClO}_{4}\right)_{2}$ complex. $\mathrm{Ru} 1$ complex is placed on the right, $\mathrm{Ru} 2$ - on the left. Anions $\left(\mathrm{ClO}_{4}^{-}\right)$and hydrogen atoms are omitted.

Table S1. Experimental and refinement details. $R$ factor of MS1 is shown for refinement only with $\mathrm{Ru}$ ON isomer, $R$ factor of MS2 - for model with partial occupation of GS, MS1 and MS2.

\begin{tabular}{|c|c|c|c|c|}
\hline & GS & MS1 & MS2 & GS after \\
\hline Formula & \multicolumn{4}{|c|}{$\mathrm{C}_{20} \mathrm{H}_{20} \mathrm{~N}_{5} \mathrm{O}_{9} \mathrm{~F}_{1} \mathrm{Cl}_{2} \mathrm{Ru}$} \\
\hline Formula weight & \multicolumn{4}{|c|}{665.38} \\
\hline Temperature/K & \multicolumn{3}{|c|}{100} & 293 \\
\hline Crystal system & \multicolumn{4}{|c|}{ Triclinic } \\
\hline Space group & \multicolumn{4}{|c|}{$\mathrm{P} \overline{1}$} \\
\hline $\mathrm{a} / \AA$ & $10.426(1)$ & $10.494(1)$ & $10.438(1)$ & $10.5287(9)$ \\
\hline $\mathrm{b} / \AA$ & $16.431(2)$ & $16.349(2)$ & $16.407(2)$ & $16.640(2)$ \\
\hline $\mathrm{c} / \AA$ & $16.397(2)$ & $16.368(2)$ & $16.413(2)$ & $16.699(2)$ \\
\hline$\alpha /^{\circ}$ & $65.866(4)$ & $65.582(3)$ & $65.912(4)$ & $65.407(3)$ \\
\hline$\beta /^{\circ}$ & $82.813(4)$ & $82.680(3)$ & $82.720(4)$ & $82.816(3)$ \\
\hline$\gamma /{ }^{\circ}$ & $87.451(4)$ & $88.181(3)$ & $87.832(4)$ & $87.979(3)$ \\
\hline Volume $/ \AA^{3}$ & $2543.2(5)$ & $2535.4(4)$ & $2544.9(5)$ & $2638.9(4)$ \\
\hline $\mathrm{Z} / \mathrm{Z}^{\prime}$ & \multicolumn{4}{|c|}{$2 / 2$} \\
\hline$\rho_{\text {calc }} \mathrm{g} / \mathrm{cm}^{3}$ & 1.738 & 1.743 & 1.737 & 1.675 \\
\hline$\mu / \mathrm{mm}^{-1}$ & 0.893 & 0.896 & 0.893 & 0.861 \\
\hline $\mathrm{F}(000)$ & \multicolumn{4}{|c|}{1336.0} \\
\hline Crystal size $/ \mathrm{mm}^{3}$ & \multicolumn{4}{|c|}{$0.228 \times 0.213 \times 0.192$} \\
\hline Radiation & \multicolumn{4}{|c|}{$\operatorname{MoK} \alpha(\lambda=0.71073)$} \\
\hline
\end{tabular}




\begin{tabular}{|c|c|c|c|c|}
\hline $\begin{array}{c}2 \Theta \text { range for data } \\
\text { collection }^{\circ}\end{array}$ & $\begin{array}{l}2.716 \text { to } \\
76.118\end{array}$ & $\begin{array}{l}2.736 \text { to } \\
71.646\end{array}$ & $\begin{array}{l}2.72 \text { to } \\
72.556\end{array}$ & $\begin{array}{l}2.692 \text { to } \\
61.274\end{array}$ \\
\hline Index ranges & $\begin{array}{c}-18 \leq \mathrm{h} \leq 18 \\
-28 \leq \mathrm{k} \leq 28 \\
-27 \leq 1 \leq 27\end{array}$ & $\begin{array}{c}-17 \leq \mathrm{h} \leq 17 \\
-26 \leq \mathrm{k} \leq 26 \\
-26 \leq 1 \leq 26\end{array}$ & $\begin{array}{c}-17 \leq \mathrm{h} \leq 17 \\
-27 \leq \mathrm{k} \leq 27 \\
-27 \leq 1 \leq 27\end{array}$ & $\begin{array}{l}15 \leq \mathrm{h} \leq 14, \\
-23 \leq \mathrm{k} \leq 23, \\
-23 \leq 1 \leq 23\end{array}$ \\
\hline Reflections collected & 163780 & 200391 & 170726 & 122480 \\
\hline Independent reflections & $\begin{array}{c}26806\left[\mathrm{R}_{\text {int }}=\right. \\
0.0462 \\
\mathrm{R}_{\text {sigma }}= \\
0.0321]\end{array}$ & $\begin{array}{c}23648\left[\mathrm{R}_{\text {int }}=\right. \\
0.0491 \\
\mathrm{R}_{\text {sigma }}= \\
0.0254]\end{array}$ & $\begin{array}{c}24469\left[\mathrm{R}_{\text {int }}=\right. \\
0.0583, \\
\mathrm{R}_{\text {sigma }}= \\
0.0347]\end{array}$ & $\begin{array}{c}16105\left[\mathrm{R}_{\text {int }}=\right. \\
0.0327 \\
\mathrm{R}_{\text {sigma }}= \\
0.0205]\end{array}$ \\
\hline Data/restraints/parameters & $26806 / 0 / 686$ & $23648 / 0 / 733$ & $24469 / 0 / 751$ & $16105 / 0 / 685$ \\
\hline Goodness-of-fit on $\mathrm{F}^{2}$ & 1.051 & 1.085 & 1.046 & 1.045 \\
\hline $\begin{array}{l}\text { Final } \mathrm{R} \text { indexes } \\
\qquad[\mathrm{I}>=2 \sigma(\mathrm{I})]\end{array}$ & $\begin{array}{c}\mathrm{R}_{1}=0.0333 \\
\mathrm{wR}_{2}=0.0755\end{array}$ & $\begin{array}{c}\mathrm{R}_{1}=0.0346 \\
\mathrm{wR}_{2}=0.0784\end{array}$ & $\begin{array}{c}\mathrm{R}_{1}=0.0400 \\
\mathrm{wR}_{2}=0.0944\end{array}$ & $\begin{aligned} \mathrm{R}_{1} & =0.0431 \\
\mathrm{wR}_{2} & =0.1210\end{aligned}$ \\
\hline Final $\mathrm{R}$ indexes [all data] & $\begin{array}{c}\mathrm{R}_{1}=0.0463 \\
\mathrm{wR}_{2}=0.0847\end{array}$ & $\begin{array}{c}\mathrm{R}_{1}=0.0469 \\
\mathrm{wR}_{2}=0.0872\end{array}$ & $\begin{array}{c}\mathrm{R}_{1}=0.0536 \\
\mathrm{wR}_{2}=0.1045\end{array}$ & $\begin{array}{c}\mathrm{R}_{1}=0.0621 \\
\mathrm{wR}_{2}=0.1407\end{array}$ \\
\hline $\begin{array}{c}\text { Largest diff. peak/hole / } \\
\text { e } \AA^{-3}\end{array}$ & $1.82 /-1.63$ & $1.81 /-1.04$ & $1.51 /-1.31$ & $1.03 /-0.73$ \\
\hline
\end{tabular}

Table S2. Selected bond distances and angles of GS, MS1 and MS2 isomers.

\begin{tabular}{|c|c|c|c|c|}
\hline Distance/angle [̊/ $\left.{ }^{\circ}\right]$ & GS & MS1 & MS2 (GS for Ru1) & GS after relaxation \\
\hline Ru1-N11 & $1.751(1)$ & - & $1.800(7)$ & $1.760(2)$ \\
\hline Ru1-O111 & - & $1.842(1)$ & - & - \\
\hline N11-O111 & $1.141(2)$ & $1.146(2)$ & $1.10(1)$ & $1.127(4)$ \\
\hline Ru1-N11-O111 & $177.5(1)$ & - & $176.4(8)$ & $177.7(3)$ \\
\hline Ru1-O111-N11 & - & $177.7(1)$ & - & - \\
\hline Ru1-F1 & $1.960(1)$ & $1.943(1)$ & $1.952(1)$ & $1.954(2)$ \\
\hline Ru1-N12 & $2.097(2)$ & $2.096(2)$ & $2.094(2)$ & $2.104(3)$ \\
\hline Ru1-N13 & $2.090(1)$ & $2.085(1)$ & $2.086(1)$ & $2.091(2)$ \\
\hline Ru1-N14 & $2.087(2)$ & $2.085(2)$ & $2.086(2)$ & $2.096(3)$ \\
\hline Ru1-N15 & $2.094(1)$ & $2.085(1)$ & $2.087(1)$ & $2.097(2)$ \\
\hline \multicolumn{7}{|r|}{} & $1.750(1)$ & - & $2.00(2)$ & $1.757(3)$ \\
\hline
\end{tabular}




\begin{tabular}{|c|c|c|c|c|}
\hline $\mathrm{Ru} 2-\mathrm{O} 211$ & - & $1.841(1)$ & $2.09(1)$ & - \\
\hline $\mathrm{N} 21-\mathrm{O} 211$ & $1.141(2)$ & $1.146(2)$ & $1.03(2)$ & $1.135(5)$ \\
\hline $\mathrm{Ru} 2-\mathrm{N} 21-\mathrm{O} 211$ & $179.1(1)$ & - & $80(1)$ & $178.7(3)$ \\
\hline $\mathrm{Ru} 2-\mathrm{O} 211-\mathrm{N} 21$ & - & $178.7(1)$ & $71(1)$ & - \\
\hline $\mathrm{Ru} 2-\mathrm{F} 2$ & $1.914(1)$ & $1.898(1)$ & $1.907(1)$ & $1.908(2)$ \\
\hline $\mathrm{Ru} 2-\mathrm{N} 22$ & $2.098(1)$ & $2.091(1)$ & $2.092(1)$ & $2.098(2)$ \\
\hline $\mathrm{Ru} 2-\mathrm{N} 23$ & $2.098(2)$ & $2.091(2)$ & $2.092(2)$ & $2.096(3)$ \\
\hline $\mathrm{Ru} 2-\mathrm{N} 24$ & $2.103(2)$ & $2.095(1)$ & $2.100(2)$ & $2.099(3)$ \\
\hline $\mathrm{Ru} 2-\mathrm{N} 25$ & $2.092(1)$ & $2.086(2)$ & $2.089(2)$ & $2.098(3)$ \\
\hline
\end{tabular}

Table S3. Selected angles and torsion angles in $[\mathrm{RuNOPy} 4 \mathrm{~F}]\left(\mathrm{ClO}_{4}\right)_{2}$ complex.

\begin{tabular}{|c|c|c|c|c|}
\hline Angle $\left[{ }^{\circ}\right]$ & GS & $\begin{array}{l}\text { MS1 (O111 and O211 } \\
\text { instead of N11 and } \\
\text { N21) }\end{array}$ & $\begin{array}{c}\text { MS2 (N212 instead of } \\
\text { N21) }\end{array}$ & GS after \\
\hline N12-Ru1-N11 & $92.83(6)$ & $91.46(6)$ & $92.1(2)$ & $93.1(1)$ \\
\hline N13-Ru1-N11 & $94.64(6)$ & $93.13(7)$ & $94.1(2)$ & $94.1(1)$ \\
\hline N14-Ru1-N11 & $93.81(6)$ & $92.76(6)$ & $93.6(2)$ & $93.5(1)$ \\
\hline N15-Ru1-N11 & $92.60(6)$ & $92.32(6)$ & $92.6(2)$ & $92.4(1)$ \\
\hline F1-Ru1-N11 & $177.97(5)$ & $178.38(5)$ & $178.0(2)$ & $178.5(1)$ \\
\hline C121-N12-Ru1-N11 & 131.3(1) & 131.1(1) & $131.0(3)$ & $131.3(2)$ \\
\hline C131-N13-Ru1-N11 & $154.0(1)$ & $154.1(2)$ & $152.9(4)$ & $151.2(3)$ \\
\hline C141-N14-Ru1-N11 & $140.2(1)$ & 141.1(1) & $140.8(3)$ & $140.9(3)$ \\
\hline C151-N15-Ru1-N11 & $141.0(1)$ & $141.8(1)$ & $141.9(4)$ & $142.6(3)$ \\
\hline N22-Ru2-N21 & $93.34(6)$ & $93.10(6)$ & $93.04(9)$ & $93.6(1)$ \\
\hline N23-Ru2-N21 & $94.64(6)$ & $93.48(6)$ & $94.42(9)$ & $93.9(1)$ \\
\hline N24-Ru2-N21 & $94.64(6)$ & $92.75(6)$ & $94.12(9)$ & $93.6(1)$ \\
\hline N25-Ru2-N21 & $93.29(6)$ & $92.50(6)$ & $93.53(9)$ & $93.3(1)$ \\
\hline F2-Ru2-N21 & $178.78(5)$ & $179.30(5)$ & $178.82(9)$ & $179.3(1)$ \\
\hline C221-N22-Ru2-N21 & 149.3(1) & $149.4(1)$ & $149.0(2)$ & $150.0(3)$ \\
\hline C231-N23-Ru2-N21 & $146.2(1)$ & $149.2(1)$ & $146.8(2)$ & $147.8(3)$ \\
\hline C241-N24-Ru2-N21 & $159.3(1)$ & $145.6(2)$ & $159.0(2)$ & $157.2(3)$ \\
\hline C251-N25-Ru2-N21 & $137.4(1)$ & $136.9(1)$ & $136.8(2)$ & $138.3(3)$ \\
\hline
\end{tabular}




\section{MS1 structure refinement}

After irradiation of the same single crystal with blue light $(420 \mathrm{~nm}, 60 \mathrm{~min}, 500 \mathrm{~mW})$, the color of the crystal changed from bright yellow to deep green (See Figure S3) and the structural parameters have been collected again. Lattice parameters changed as well, as illustrated in Table S1. The $a$ constant, which mainly corresponds to the axis along the ruthenium-nitrosyl coordinate elongated from 10.426(1) to 10.494(1) $\AA$ $(0.6 \%)$, while $b$ and $c$ constants decreased from 16.431(2) and 16.397(2) $\AA$ to $16.349(2)(0.5 \%)$ and $16.368(2) \AA(0.2 \%)$, respectively. For the determination of the atomic position we apply an approach that was used earlier ${ }^{[3]}{ }^{[4]}$. The structure was solved with three different models: $a$ - with Ru-NO bonds; $b$ with $\mathrm{Ru}-\mathrm{ON}$ bonds; $c$ - with both $\mathrm{Ru}-\mathrm{NO}$ and $\mathrm{Ru}-\mathrm{ON}$ linkage types. Then, the residual electron density maps for each type of refinement were drawn and analyzed (See Figure S4). The map obtained using model $a$ shows significant excess of electrons around the nitrogen atom and a corresponding depletion of electron density around the oxygen atom of the nitrosyl ligand, which indicates that a more electron rich atom should be placed at the GS nitrogen position and a less electron rich atom at the GS oxygen position. In the case of a structure refinement with Ru-ON groups (Figure S4, model $b$ ), no significant excess or depletion of electron density around the isonitrosyl ligands is observed, indicating that the occupation of this type of isomers is close to full. Finally, the disordered structure with both a Ru-NO and a Ru-ON configuration (model $c$ ) does not demonstrate any depletion or excess of electron density around iso- and nitrosyl ligands either. In this case, the occupancies of Ru1-O111-N11 and Ru2-O211-N21 groups are 95 and 89\%, corresponding to an almost full GS - MS1 conversion. Unfortunately, Ru-NO of the remaining 5 and $11 \%$ GS could not be refined with anisotropic displacement parameters due to the low occupancy. For an indepth discussion of the correlation between population and structural and anisotropic displacement parameters we refer the reader to the work by Cormary et al. ${ }^{[2]}$. As the populations of MS1 are almost $100 \%$, we give only the parameters obtained from model $b$ in the Tables S1, S2 and S3. The Ru-O bond distances in Ru-ON are 1.842(1) and 1.841(1) $\AA$ for Ru1 and Ru2 respectively. Clearly, in MS1 Ru-ON bond distances are longer by 0.091(1) $\AA$ compared to GS, and this is the most drastic change in bond distances after light exposure. N-O distances are slightly elongated - 1.146(2) A. Ru1-O111-N11 and Ru2-O211$\mathrm{N} 21$ angles are still close to linear $-177.7(1)$ and $178.7(1)^{\circ}$. Ru-F distances decreased by $0.017(1)$ and $0.016(1) \AA$ compared to GS to Ru1-F1 = 1.943(1) $\AA$ and Ru2-F2 = 1.898(1) $\AA$. The average distances between $\mathrm{Ru}$ and planar $\mathrm{N}$ atoms of pyridine are 2.088(3) and 2.091(2) $\AA$ for Ru1 and Ru2 respectively, which decreased by 0.004(3) and 0.007(2) A, compared to GS. The average angles between N pyridine atom, ruthenium and $\mathrm{O} 111(\mathrm{O} 211)$ atom of isonitrosyl ligand are 92.4(4) and 93.0(2) ${ }^{\circ}$ for Ru1 and Ru2 respectively, corresponding to an upward tilting of the pyridine rings by 1.1(5) and 1.0(4) ${ }^{\circ}$. Pyridine torsions are changed as well after NO isomerization. One of the pyridine ring propeller change the 
orientation drastically by $13.7(2)^{\circ}$ (See Table S3). While the displacement parameters of pyridine rings remain the same before and after isomerization, the significantly increased displacement parameters of the perchlorate oxygen atoms indicate a disorder over two positions of the perchlorate counter ions after isomerization. The N-O closest distances between nitrosyl and perchlorate for Ru1 are: N11-O43 - 2.725(4)

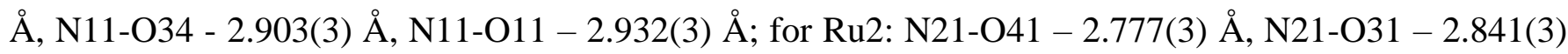
$\AA$, N21-O21 - 2.74(4) A. Probably, the interaction between the nitrosyl group and the perchlorate changes after isomerization and thus affects the disordering of oxygen positions, which results in an increase of the thermal displacement parameters. In general, changing of the linkage from $\mathrm{Ru}-\mathrm{NO}$ to $\mathrm{Ru}-\mathrm{ON}$ affects all bond distances and angles in the ruthenium octahedron and the second coordination sphere. With elongation of the Ru-ON coordinate, the structure adapts to the new linkage - thereby affecting the other distances and angles in the first coordination sphere. Our structural refinement indicates an MS1 isomer with almost $100 \%$ population, while from IR data, the population of MS1 was only $40 \%$. This difference might be due to the different nature of the sample (powder in $\mathrm{KBr}$ pellet vs single crystal). Note that this is one of the three example ${ }^{[2]}{ }^{[3]}$ with the highest MS1 population, which shows how the whole structure changes after a rather small rearrangement of one ligand.
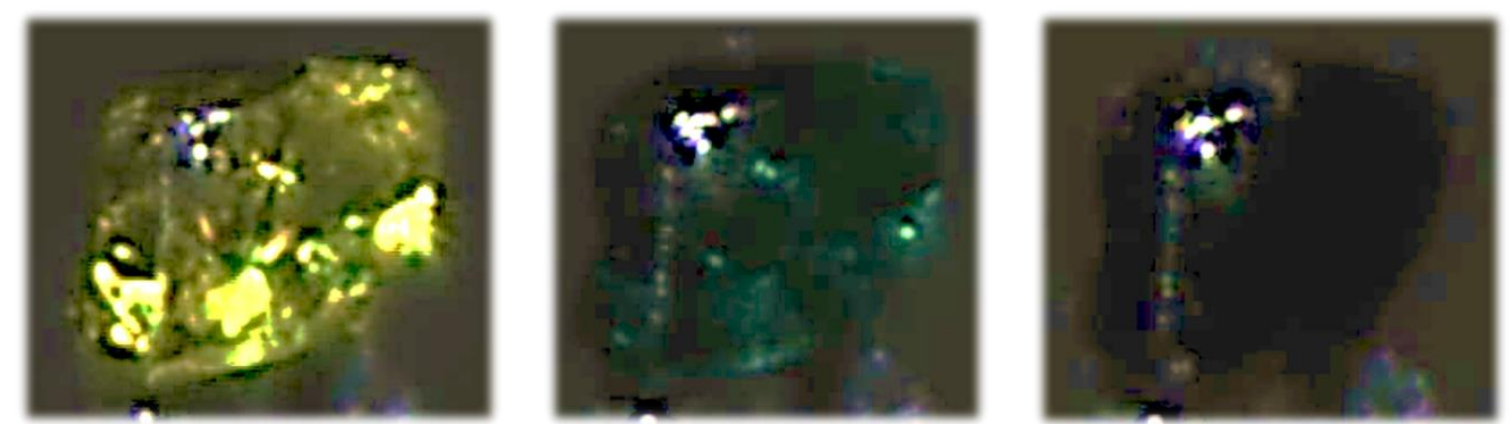

Figure S3. The color of single crystal of $[\mathrm{RuNOPy} 4 \mathrm{~F}]\left(\mathrm{ClO}_{4}\right)_{2}$ complex in GS (left, yellow), MS1 (middle, deep green) and MS2 (right, black). 

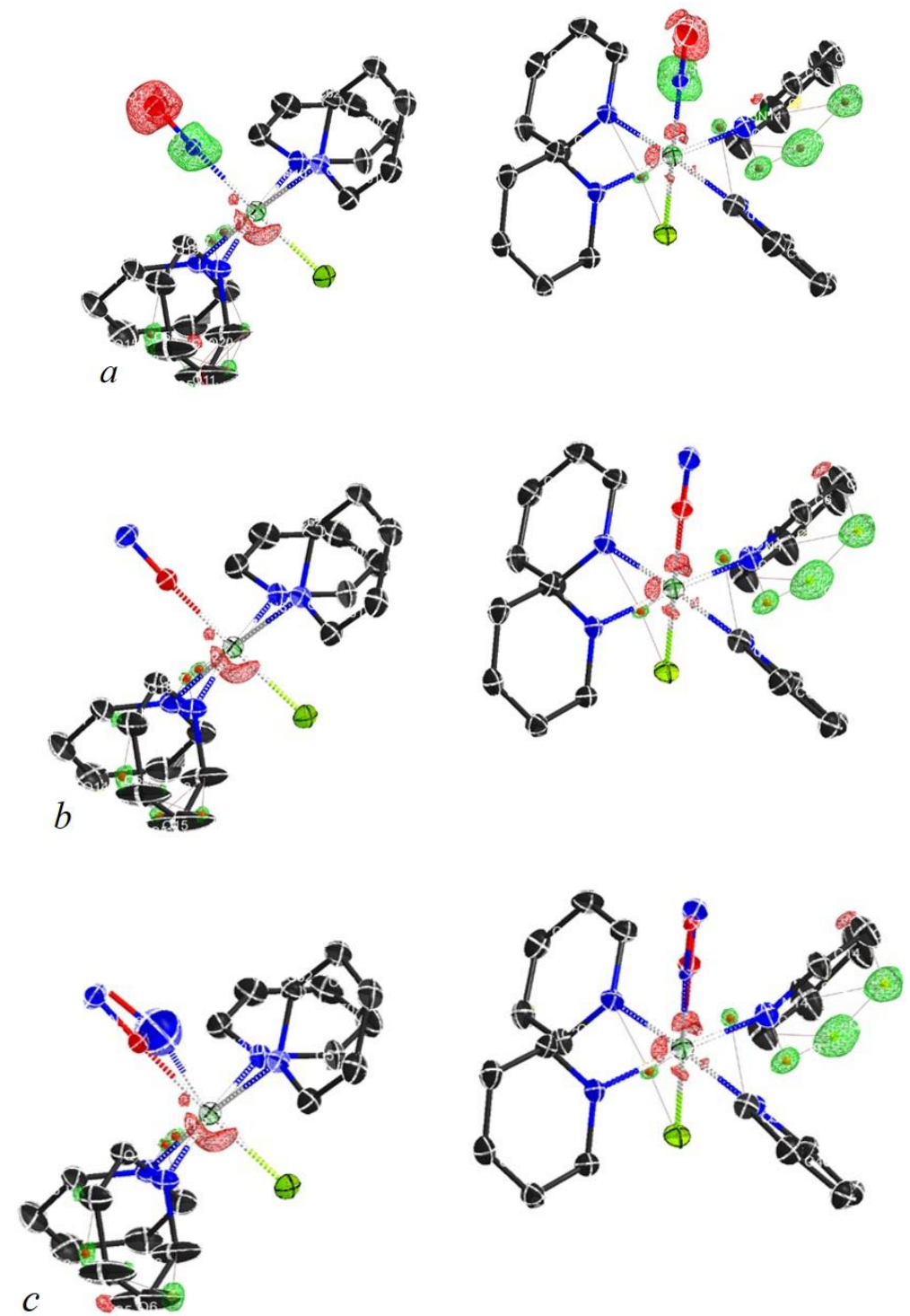

Figure S4. Residual electron density maps of structure refinement with Ru-NO ( $a$, top), Ru-ON ( $b$, middle) groups and both groups ( $c$, bottom). Occupancies of Ru-NO isomers in the last model are 5 and

$11 \%$ for Ru1 and Ru2 respectively. Ru1 fragment is placed on the left, Ru2 - on the right. Excess of electrons is shown by the green color, depletion by the red color. The residual electron density surfaces are $0.4 \mathrm{e}^{-3}$.

\section{MS2 structure refinement}

After subsequent irradiation of the same single crystal with infrared light $(920 \mathrm{~nm}, 30 \mathrm{~min}, 400 \mathrm{~mW})$ the color of the crystal changed from deep green to black (See Figure S3), and the structural parameters have been collected again. The cell parameters changed with a trend back towards those of GS $-a$ decreased, $b$ and $c$ increased. The structure was solved and refined using different models as discussed below. During the refinement, an electronic density corresponding to the MS2 isomer was detected only in the Ru2 fragment. Residual electron density maps of the different refinement models are shown in Figure S5. Interestingly we observe an MS2 population only for the Ru2 complex. The reason for this difference is at 
the moment not clear, we can only speculate about possible origins. We know that the ligand trans to nitrosyl has a strong influence on the photoisomerization ${ }^{[5]}$, we therefore suppose that the difference in $\mathrm{Ru}$ $\mathrm{F}$ bond lengths of the two non-equivalent $\mathrm{Ru} 1$ and $\mathrm{Ru} 2$ complexes is responsible for the different MS2 populations. In the case of a structure refinement assuming a Ru-NO group (See Figure S5, $a$ ), we can clearly distinguish an excess of electrons in the perpendicular plane near the nitrosyl group in Ru2. Moreover, there is depletion of electrons near the oxygen atom of the nitrosyl ligand. Both observations shows us, that all three possible states - GS, MS1 and MS2 are present in Ru2, i.e. the transfer from MS1 to MS2 is not complete. According to Ru-ON refinement (Figure S8, b), excess of electrons in the perpendicular plane of nitrosyl of Ru2 shows up again as well as depletion of electrons near the oxygen atom of the nitrosyl ligand. In the last model, we laid two Ru-NO and Ru-( $\left.\eta^{2}-(\mathrm{NO})\right)$ groups in the Ru2 structure (Figure S8, c). This refinement does not demonstrate any lack or excess of electrons around the nitrosyl ligands. Even with only $17 \%$ occupancy of MS2 isomer, we can unambiguously refine the MS2 structure, as it is located perpendicular to the GS or MS1 coordinate. However, due to the low occupancy, we could not manage to refine $\mathrm{Ru}-\left(\eta^{2}-(\mathrm{NO})\right)$ with anisotropic displacement parameters. As was mentioned above, in this system all three possible linkage states are present, thus, we limit our discussion to the changes related to the nitrosyl ligand of MS2. The structure of MS2 is presented in Figure S6. Ru2-N21 bond length is 2.00(2) $\AA$, Ru2-O211 bond is longer - 2.09(1) $\AA$, which is in agreement with MS2 structural data of the

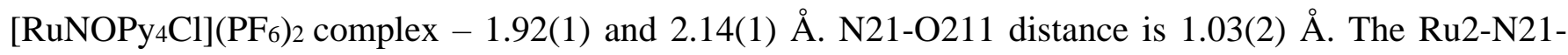
$\mathrm{O} 211$ angle is $80(1)^{\circ}$, which is close to $90^{\circ}, \mathrm{Ru} 2-\mathrm{O} 211-\mathrm{N} 21=71(1)^{\circ} . \mathrm{Ru} 2-\mathrm{N} 212$ bond of the remaining GS component is $1.765(2) \AA$, N212-O212 = 1.152(3) $\AA$, slightly different from GS structure before irradiation. This suggests again, that in the system the MS1 isomer is also present. In Ru1 complex only MS1 (population is 47\%) and GS were found. Distances of GS are presented in Table S1. Ru1-O112 $(\mathrm{MS} 1)=$ 1.78(1) $\mathrm{A}, \mathrm{N} 112-\mathrm{O} 112=1.17(1) \AA$. Again, in case of non $~ 100 \%$ of state, MS1 and GS distances differ from data discussed in the previous GS and MS1 refinement sections. The population dependence of MS1 and GS distance changes was shown in ${ }^{[2]}$. To be sure, that after all irradiation procedures the system relaxes back to GS, the same crystal was heated up to room temperature and data were collected again after several days. Crystal data and selected distances/angles are shown in Tables S1, S2 and S3 and corresponds to the GS before irradiation bearing in mind, that data were collected at room temperature, but not at $100 \mathrm{~K}$. 

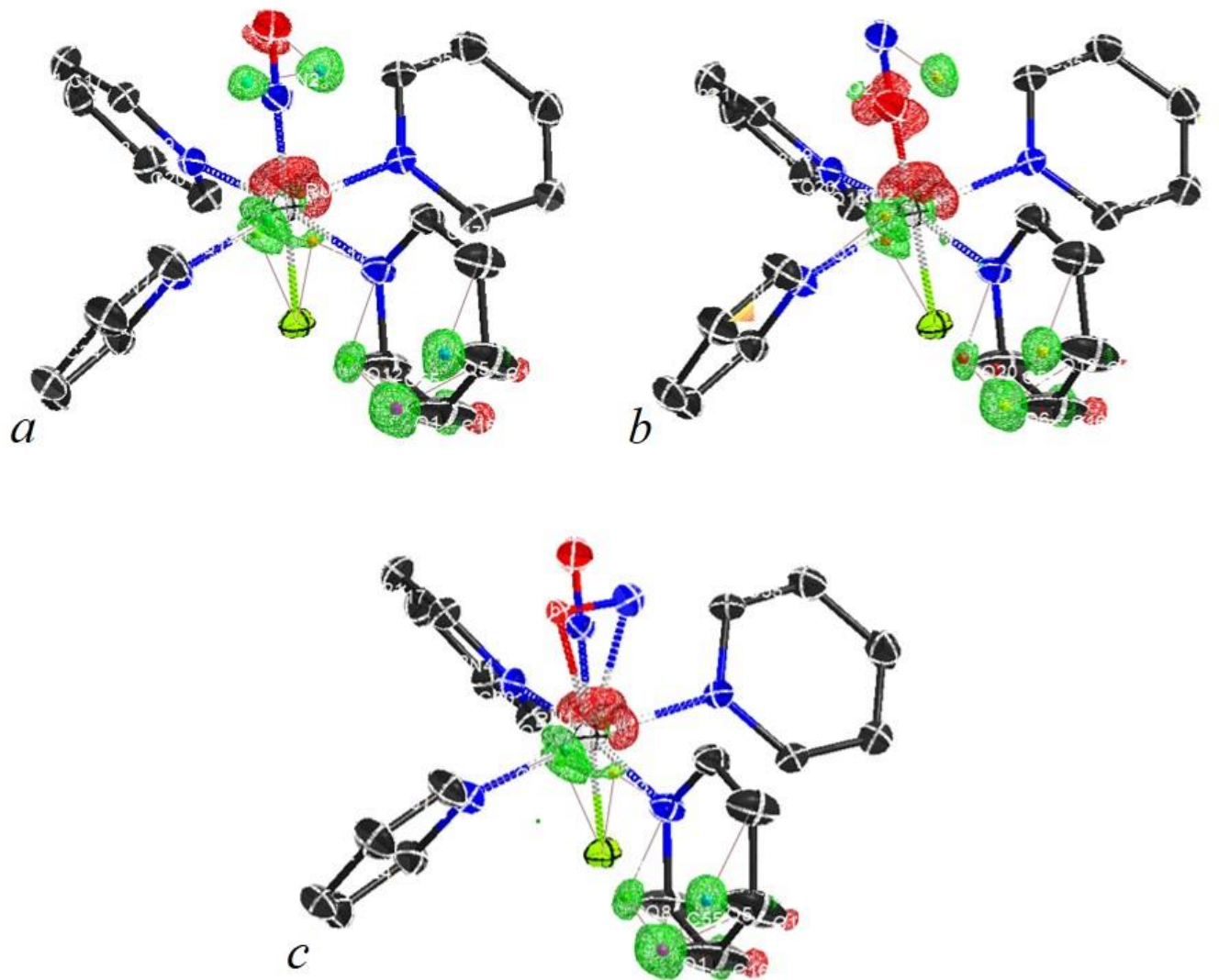

Figure S5. Residual electron density maps of structure refinement with $\mathrm{Ru}-\mathrm{NO}$ ( $a$, top, left), $\mathrm{Ru}-\mathrm{ON}$ ( $b$, top, right) groups and both Ru-NO and Ru-( $\left.\eta^{2}-(\mathrm{NO})\right)\left(c\right.$, bottom). Occupancy of Ru-( $\left.\eta^{2}-(\mathrm{NO})\right)$ isomer in the last model is $17 \%$. Only Ru2 fragment is presented due to absence of MS2 isomer in Ru1 fragment. Excess of electrons are shown by the green color, depletion by the red color. The residual electron density surfaces are $0.4 \mathrm{e}^{-3}$.

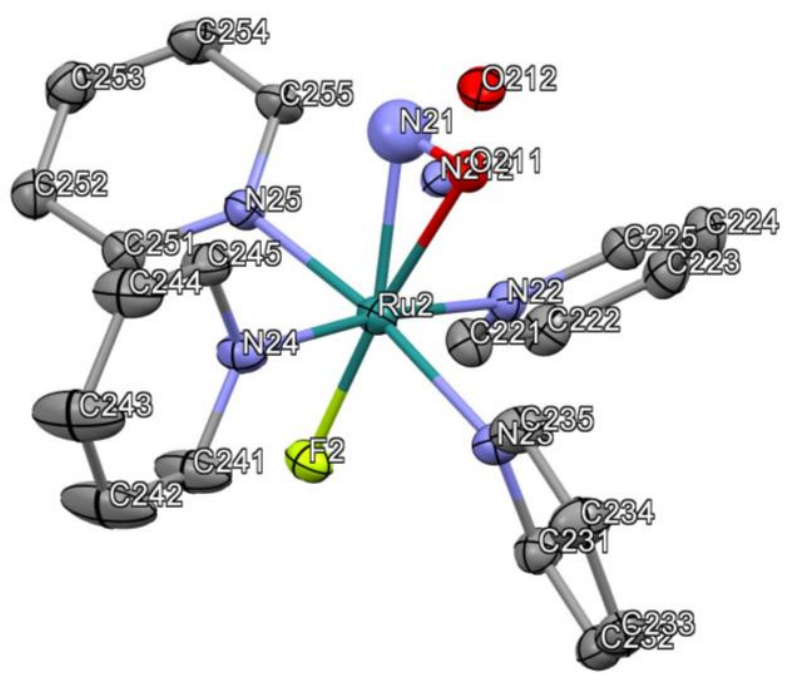


Figure S6. Structure of $\left[\mathrm{RuNOPy}_{4} \mathrm{~F}\right]\left(\mathrm{ClO}_{4}\right)_{2}$ complex $(\mathrm{Ru} 2$ particle) refined with both $\mathrm{Ru}-$ $\mathrm{NO}$ and $\mathrm{Ru}-\left(\eta^{2}-(\mathrm{NO})\right)$ groups. Occupancy of $\mathrm{Ru}-\left(\eta^{2}-(\mathrm{NO})\right)$ isomer is $17 \%$. Anions $\left(\mathrm{ClO}_{4}^{-}\right)$ and hydrogen atoms are omitted.

\section{Spectroscopy studies}
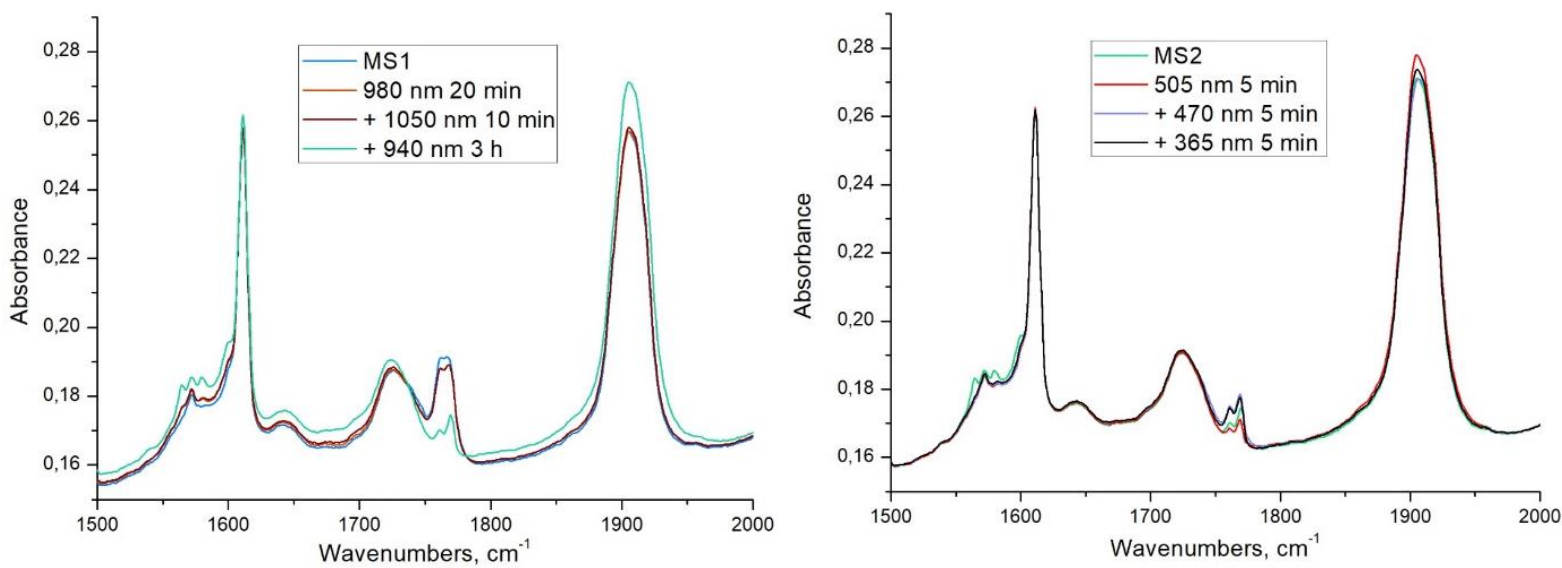

Figure S7. (left) IR spectra during MS1-MS2 transfer with infrared light: spectrum of MS1 (blue), after $20 \mathrm{~min}$ of $980 \mathrm{~nm}$ irradiation (orange), after $10 \mathrm{~min}$ of $1050 \mathrm{~nm}$ irradiation (brown), and after $3 \mathrm{~h}$ of $940 \mathrm{~nm}$ irradiation (green). (right) IR spectra during MS2-GS transfer: spectrum of MS2 (green), after $5 \mathrm{~min}$ of $505 \mathrm{~nm}$ irradiation (red), after $5 \mathrm{~min}$ of 470 $\mathrm{nm}$ irradiation (blue), and after $5 \mathrm{~min}$ of $365 \mathrm{~nm}$ irradiation (black).

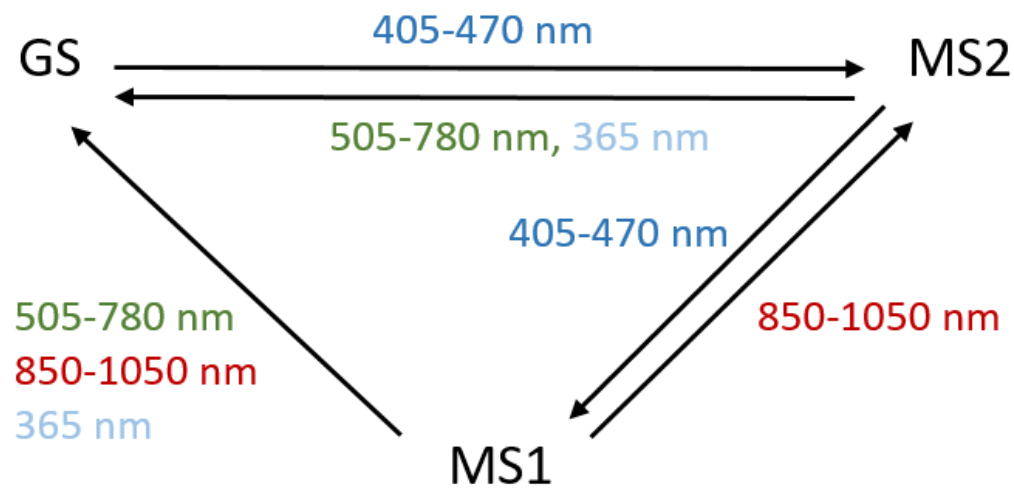

Figure S8. Scheme of linkage isomerization in $\left[\mathrm{RuNO}(\mathrm{Py})_{4} \mathrm{~F}\right]\left(\mathrm{ClO}_{4}\right)_{2}$ indicating relevant spectral ranges for population and depopulation with light.

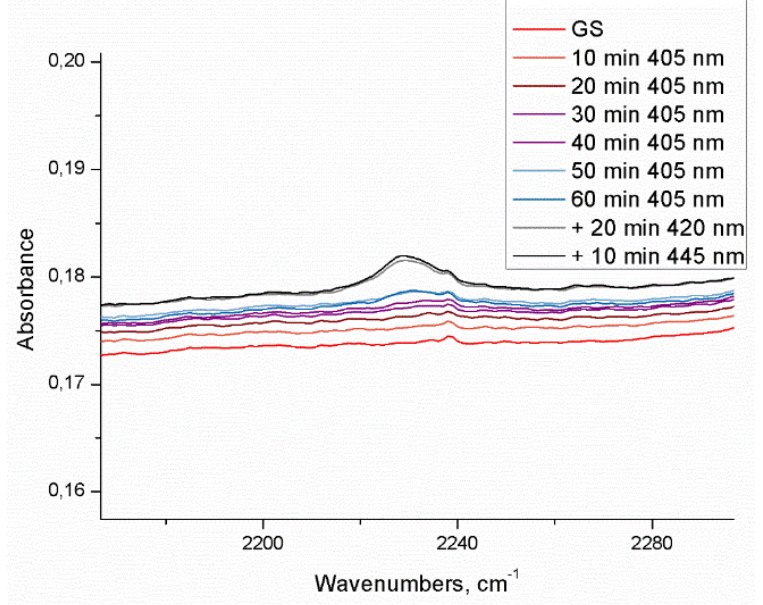


Figure S9. The band at $2230 \mathrm{~cm}^{-1}$, which appears after more than 60 min irradiation by blue light. The band presumably corresponds to the frequency vibration of $\mathrm{N}_{2} \mathrm{O}$ formed after the partial NO release from the $\left[\mathrm{RuNO}(\mathrm{Py})_{4} \mathrm{~F}\right]\left(\mathrm{ClO}_{4}\right)_{2}$ complex.
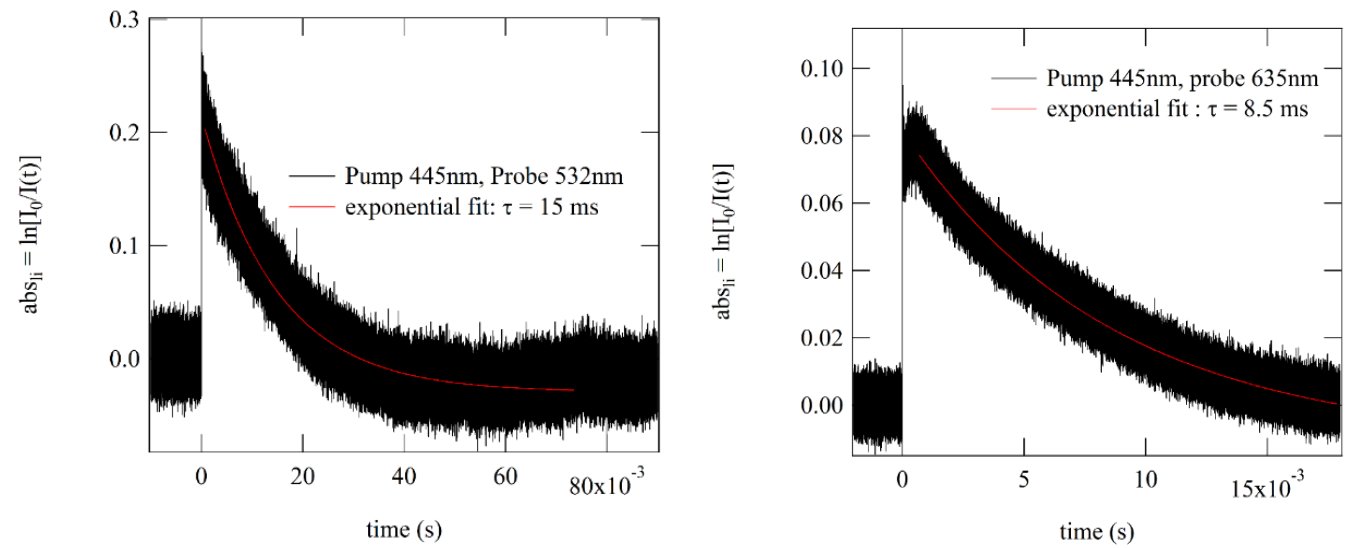

Figure S10. Absorption changes in $[\mathrm{RuNOPy} 4 \mathrm{~F}]\left(\mathrm{ClO}_{4}\right)_{2}$ single crystal after excitation with a

$5 \mathrm{~ns}$ LASER pulse at $445 \mathrm{~nm}$ and probing at $532 \mathrm{mn}$ (left) and $635 \mathrm{~nm}$ (right). The experimental data is fitted by mono-exponential kinetic yielding lifetimes of 15 and $8.5 \mathrm{~ms}$ for the 532 and $635 \mathrm{~nm}$ probe wavelength, respectively.

\section{References}

[1] G. A. Kostin, A. A. Mikhailov, N. V Kuratieva, D. P. Pishchur, A. N. Makhinya, New J. Chem. 2018, 42, 18928-18934.

[2] B. Cormary, I. Malfant, M. Buron-Le Cointe, L. Toupet, B. Delley, D. Schaniel, N. Mockus, T. Woike, K. Fejfarová, V. Petř́íček, et al., Acta Crystallogr. Sect. B Struct. Sci. 2009, 65, 612-623.

[3] G. A. Kostin, A. O. Borodin, A. A. Mikhailov, N. V. Kuratieva, B. A. Kolesov, D. P. Pishchur, T. Woike, D. Schaniel, Eur. J. Inorg. Chem. 2015, 29, 4905-4913.

[4] G. A. Kostin, A. A. Mikhailov, N. V. Kuratieva, D. P. Pischur, D. O. Zharkov, I. R. Grin, New J. Chem. 2017, 41, 7758-7765.

[5] R. D. Yamaletdinov, I. L. Zilberberg, Eur. J. Inorg. Chem. 2017, 23, 2951-2954. 